\title{
STAPHYLOCOCCAL INFECTION FOLLOWING CARDIAC SURGERY
}

\author{
BY \\ H. A FLEMING AND R. M. E. SEAL \\ From Sully Hospital, Glamorgan
}

(RECEIVED FOR PUBLICATION JULY 25, 1955)

The surgery of the heart and the great vessels is already a large field, and one that will continue to expand. Large series of cases with small mortalities and morbidities have been published (Bailey, Bolton, and Redondo-Ramirez, 1952; Baker, Brock, Campbell, and Wood, 1952; Holmes Sellors, Bedford, and Somerville, 1953 ; Wood, 1954), and most of the causes of postoperative death are well recognized. However, infection has not featured prominently in these reports, and we have been unable to find reports of any post-operative staphylococcal infection of the heart or great vessels, and only passing reference (Bailey and others, 1952) to bacterial endocarditis occurring after operation.

Coagulase-negative staphylococci are generally regarded as non-pathogenic, though these organisms have been recognized as aetiological in cases of subacute bacterial endocarditis (Cates and Christie, 1951 ; Dowling, Lepper, Caldwell, and Spies, 1952).

The purpose of this paper is to present nine cases where vascular staphylococcal infection appears to have contributed to serious postoperative complications, and in three of these the organism was of the " non-pathogenic," coagulase-negative variety. Seven of these followed mitral valvotomy and two ligation of the ductus. These cases have been collected by personal contact from four different hospitals and were operated upon by five different surgeons.

\section{CASE Reports}

CASE 1.-This was the first case observed in this series. H. S., a man aged 41 years, presented with a history of rheumatic fever at the ages of 15 and 16 years, and an attack of "pneumonia" at the age of 33 years, when heart disease was first diagnosed. After this he gradually became more dyspnoeic on exertion, with frequent haemoptyses with chest pain. He also suffered from severe tiredness and coldness of the extremities.

On examination he presented the features of mitral stenosis with moderate pulmonary hypertension, with a minor degree of aortic stenosis and incompetence. The jugular venous pressure was raised to $5 \mathrm{~cm}$. at 45 degrees, and there was a prominent " $A$ " wave. At cardiac catheterization the pulmonary artery pressure was $130 / 90 \mathrm{~mm}$.

Mitral valvotomy was planned, but was postponed because 10 days after cardiac catheterization he had a haemoptysis with pleural pain. At this time gross mitral facies became evident and tricuspid incompetence with congestive failure and a right ventricular third heart sound developed. He was treated with the anticoagulant "dindevan" for three weeks, and gradually returned to his former state.

Four days after anticoagulant therapy had been stopped the prothrombin time was normal and mitral valvotomy was performed, the clinical findings being confirmed. Calcium in the valve ring allowed only a moderately good split. The lung was noted to be very firm, "livery," and darkly pigmented, biopsy showing evidence of pulmonary hypertension and diffuse haemosiderosis. On the sixth post-operative day he developed a pulmonary infarction in the right upper lobe, and again went into right heart failure. Anticoagulant therapy was re-instituted on the following day.

There was a slight general improvement. Penicillin, one million units four times a day, was started, but the temperature continued to range from 98 to $102^{\circ} \mathrm{F}$. In the next few days there was some improvement in his general condition, but confusion was very marked at times and he became jaundiced, with a serum bilirubin of $2.6 \mathrm{mg}$. per $100 \mathrm{ml}$., attributed to pulmonary infarction, with impaired liver function due to cardiac failure.

The cardiac signs were unchanged and the failure now appeared to be under control with a full medical régime, including salt-free diet.

On the nineteenth post-operative day, blood taken for culture, while the patient was still on penicillin, grew a coagulase-negative staphylococcus, which was regarded as a contaminant. Two days later mental confusion became more marked and the patient was incontinent of urine and faeces. Full neurological examination, including lumbar puncture, revealed no abnormality. Cardiac signs were unchanged, the spleen could not be felt, and no petechiae could be found. 


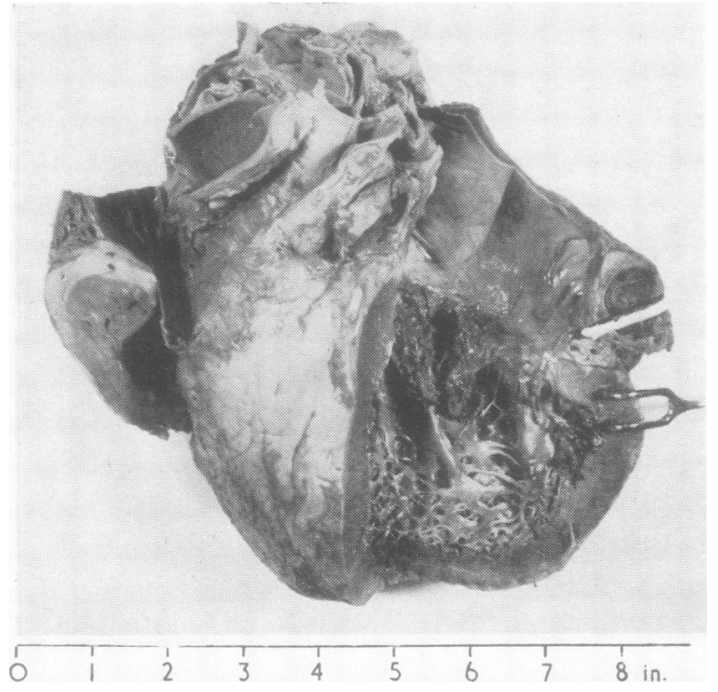

FIG. 1.-The heart in Case 1 showing the extensive vegetations on the mitral valve (see also Fig. 2) and the thrombus in the left atrium.

The mental confusion became complete and further pulmonary infarcts occurred in spite of continued controlled anticoagulant therapy. His general condition deteriorated, he lapsed into coma, and petechiae appeared on the chest shortly before his death on the 42 nd post-operative day.

Relevant Post-mortem Findings.-There was a fine purpuric rash on the front of the chest and abdomen.

The heart was enlarged and weighed $700 \mathrm{~g}$. The left atrium, right atrium, and right ventricle were dilated and hypertrophied, the left ventricle being hypertrophied and slightly dilated. There was a firm thrombus filling the left auricle with a concave atrial border (Fig. 1). There was no evidence of infection of the auricular sutures. The mitral valve was stenotic with evidence of earlier partial splitting. The posterior cusp was thick, immobile, and partly destroyed, and was covered by exuberant brownish friable vegetations, which extended to involve the posterior wall of the left atrium. The aortic valve cusps were thickened but only slightly incompetent to the water test.

The lungs were congested and oedematous with some diffuse haemosiderosis. There were healing and recent pulmonary infarcts. Both main pulmonary arteries were partially obstructed by an organizing thrombus firmly attached to the wall.

There were healing infarcts of the kidneys and spleen.

There were subpial areas of haemorrhagic cortical softening of the right frontal, left parietal, and occipital lobes of the brain.

Ante-mortem thrombus was found in the left femoral vein.

The mitral valve vegetation showed infected thrombus with numerous colonies of Gram-positive cocci (Fig. 2).
The mitral vegetation yielded a pure growth of coagulase-negative staphylococci of identical antibiotic sensitivity pattern to those grown from blood culture before death, i.e., sensitive to chloramphenicol only and resistant to penicillin, aureomycin, terramycin, and streptomycin.

Antibodies to this organism were also demonstrated in a specimen of the patient's serum retained in the laboratory.

After necropsy death was considered to be due to staphylococcal endocarditis.

CASE 2.-This was the second case observed in this series.

D. E., a woman aged 53 years, was admitted to hospital with a past history of growing pains in childhood and of four uneventful pregnancies. Her chief complaints were tiredness and dyspnoea on exertion of one year's duration. After investigation she was assessed as having moderate mitral stenosis with slight regurgitation and auricular fibrillation. The heart was moderately enlarged and there was a minor degree of aortic stenosis with incompetence.

At thoracotomy the clinical findings were substantiated and mitral valvotomy was performed. The anterior commissure was cut with a knife, but, owing to a tear in the atrial wall, the posterior commissure was not split and the mitral valve orifice now measured 2.5 by $3 \mathrm{~cm}$. The degree of mitral leak was not increased and no pressure gradient was found

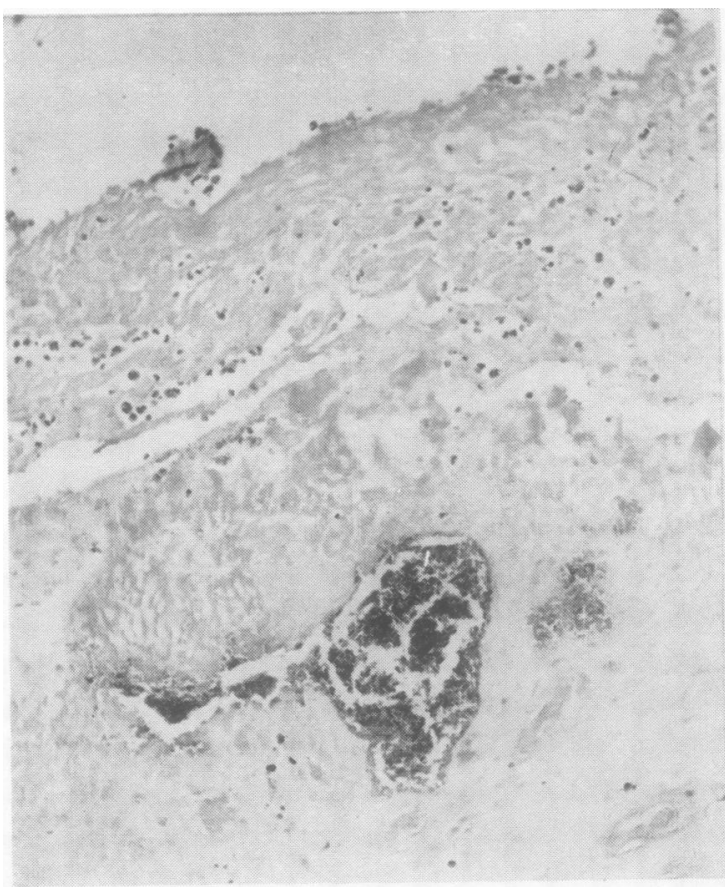

FIG. 2-Photomicrograph of vegetation on mitral valve showing colonies of staphylococci in Case 1. Haematoxylin and eosin, $\times 140$. 
across the aortic valve, before or after commissurotomy. Blood loss was fully replaced; penicillin cover was used ( 0.5 million units b.d.).

The post-operative course was at first uneventful, but on the fourth day she developed a cough, productive of rusty sputum, which continued for some days. On the seventh day it was found that the right calf was slightly swollen and tender; anticoagulant therapy with heparin and "dindevan" was instituted. She was listless and dyspnoeic at rest ; the jugular venous pressure was elevated several centimetres and there was an irregular pyrexia of up to $100^{\circ} \mathrm{F}$.

By the tenth day her general condition had improved, when she developed a Bact. coli cystitis, which was successfully treated with a four-day course of chloramphenicol. Though she was now apyrexial, she was pale and languid.

On the 24th post-operative day she had further deteriorated, and was in congestive cardiac failure with bilateral pleural effusions. Old blood-stained fluid, $700 \mathrm{ml}$., was aspirated from the right pleural cavity with considerable relief of dyspnoea. The fluid was sterile on culture. The haemoglobin was $56 \%(8.28 \mathrm{~g}$.) and $1 \frac{1}{2}$ pints of packed red cells were transfused slowly, raising the haemoglobin to $90 \%$ (13.32 g.) but without influencing her condition.

On the 28th day "dindevan" was discontinued owing to microscopic haematuria and the difficulty of obtaining blood samples.

On the 31 st day she became pyrexial with transient mental confusion, and the following day she was obviously severely ill, being incontinent and slightly jaundiced. The liver was now slightly enlarged and tender, but the cardiovascular signs and chest radiograph remained unchanged, there was no splenomegaly, no petechiae, and the optic fundi were normal. Further aspiration of the right pleural effusion yielded sterile fluid. At this stage the general picture bore a most striking resemblance to that of Case 1 at the beginning of his final illness. Because of the difficulty of venepuncture arterial blood was obtained for blood culture. Before the result of the blood culture became available the urinary infection recurred, and she was again given chloramphenicol, $500 \mathrm{mg}$., sixhourly. The blood culture grew coagulase-positive staphylococci resistant to penicillin but sensitive to terramycin, chloramphenicol, aureomycin, erythromycin, streptomycin, and sulphonamides. Chloramphenicol was continued because during the 48 hours of awaiting the result of blood culture there had been a dramatic improvement in her general condition, and she became apyrexial and the heart failure disappeared. The chloramphenicol was continued for eight weeks, by which time she was fully ambulant and in normal health; she has since remained well.

CASE 3.-P. B., a woman aged 47 years, was admitted with a past history of rheumatic fever and chorea at the age of 15 years, heart disease being diagnosed at the age of 18 years. Her chief complaints were paroxysms of palpitation for 20 years and progressive exertional dyspnoea for one year. She had four uneventful pregnancies, but the last pregnancy. five years before admission, was terminated at three months because of dyspnoea. She had been treated for paroxysmal fibrillation, and some weeks before admission had had an attack of pulmonary apoplexy. She was orthopnoeic.

On examination she was fibrillating and had all the features of severe, but pure, mitral stenosis. Mitral valvotomy was performed, using the finger, and a good split was obtained after using considerable force, but the valve did not function well due to gross calcification and to fibrosis of the chordae. It was left with a good orifice and there was no regurgitation.

The post-operative course was described as fairly satisfactory, but she ran a temperature and had intermittent pain in the chest. There was no evidence of thrombosis of leg veins, but, because of the tachycardia and occasional blood staining of the sputum. she was put on anticoagulant therapy. Her general condition improved and she looked very well, but on the 21 st day after operation she developed a queer feeling with pain in the chest and a temperature of $105^{\circ} \mathrm{F}$.; no obvious cause was found and she was put on penicillin. Following this, for the last three weeks of her life, her temperature remained high (up to $105^{\circ} \mathrm{F}$.) in spite of multiple antibiotic therapy (Fig. 3). Though she was seen by a number of people no firm diagnosis was ever made ; blood culture was not done, because she was on penicillin and it was thought that the result would be negative.

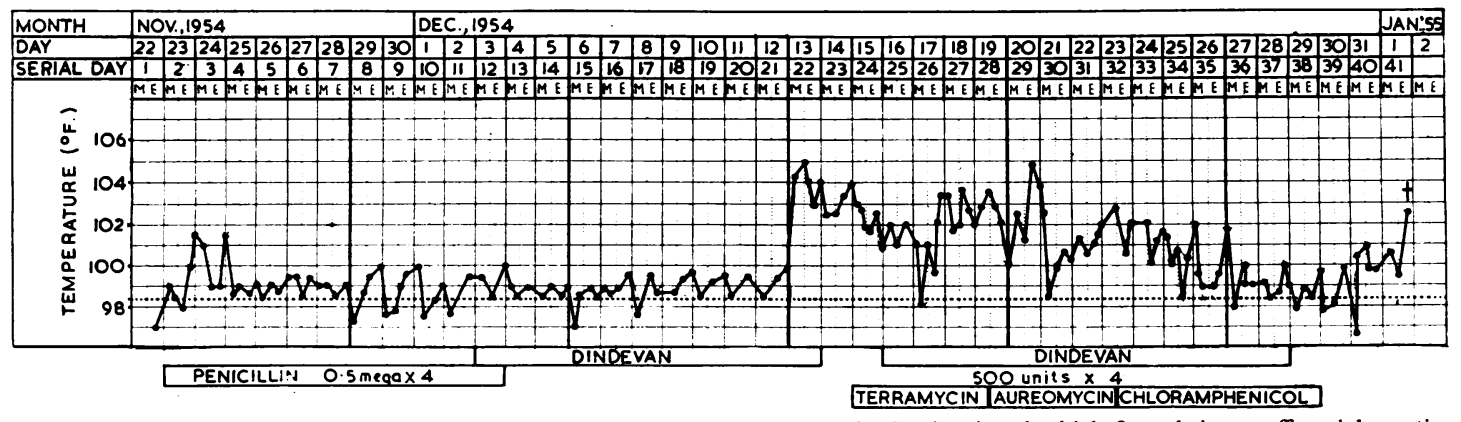

FIG. 3.-Temperature chart of Case 3 from the date of mitral valvotomy until death, showing the high fever being unaffected by antibiotics except, perhaps, chloramphenicol (the unit of dosage was mg.). 
She was coughing up thick sputum and it was thought that she might have multiple septic infarcts of the lung, but there were no clinical or radiological signs to support this.

She slowly became disorientated, and in the last 24 hours it was obvious that there was some cerebral damage. She was unconscious, she had stertorous respiration, and when lumbar puncture was done pus cells were found in the cerebrospinal fluid. The assumption was that she had a cerebral abscess.

She died in a coma 40 days after the operation.

Relevant Post-mortem Findings.---The left auricle and the right ventricle were dilated and hypertrophied. There were several small abscesses in the left auricle along the cardiotomy suture line. The mitral valve showed severe chronic rheumatic changes with shortening of the chordae tendinae, and the commissures, which had been fused, were partially torn. Both cusps were covered by extensive fibrinous vegetations, and the vegetation on the posterior cusp measured at least an inch in one axis. The infection had spread to involve the adjacent auricular and ventricular muscle. Microscopy showed large numbers of cocci in the vegetations and much of the posterior cusp was ulcerated. There were small embolic abscesses in the myocardium.

The lungs were indurated and congested, but there was no evidence of infarction or pneumonia.

There were bland and septic infarcts of the spleen. kidneys, and adrenals, and also areas of infarction of the right lobe of the liver.

There were subpial haemorrhages on the surface of the brain with two minute superficial areas of suppuration.

Coagulase-positive staphylococci were grown from the myocardial abscesses.

The cause of death was considered to be cardiac failure due to staphylococcal bacterial endocarditis.

CASE 4.-D. L., a man aged 21 years, was admitted with a past history of rheumatic fever in childhood. His chief complaints were exertional dyspnoea of moderate degree, together with paroxysmal nocturnal dyspnoea and haemoptysis of a few months' duration.

On examination he had all the signs of pure mitral stenosis without pulmonary hypertension but with auricular fibrillation.

At mitral valvotomy the lateral commissure was fully split, using a knife, and, as moderate regurgitation was produced, medial commissurotomy was not attempted; the valve orifice now, however, admitted two fingers and the atrial tension was much reduced.

The post-operative course was uneventful and the patient was getting up, when, on the 16th postoperative day, he complained of pain in the right chest. There was bronchial breathing over the right lower lobe and the temperature rose to $100.5^{\circ} \mathrm{F}$., which responded to penicillin, 0.5 million units b.d. On the 25 th day he became pyrexial $\left(98^{\circ}-101^{\circ} \mathrm{F}\right.$.) with left shoulder pain, nausea, and vomiting; petechiae were noticed in small numbers on the chest wall. There was no microscopic haematuria. but coagulase-positive staphylococci were grown from blood culture and reported as sensitive to penicillin, chloramphenicol, but resistant to streptomycin, aureomycin, and terramycin. While still on penicillin the patient was very ill and pyrexial and developed a transient effusion in the right knee joint. So terramycin, $250 \mathrm{mg}$. sixhourly, was substituted (before sensitivity results were available), and, as there was some response, this drug was continued until the 39 th post-operative day. when the patient was well enough to be allowed up. On the following day his temperature again rose $\left(98^{\circ}-\right.$ $102^{\circ} \mathrm{F}$.) and he rapidly became very ill, responding to chloramphenicol, $500 \mathrm{mg}$. six-hourly, which was continued for seven days and then replaced by penicillin, 1 million units b.d., until the 6/st post-operative day, when he was well and ambulant.

On the 66th post-operative day there was a further relapse with a return of pyrexia and left shoulder pain with general weakness and anorexia. The condition this time responded immediately to penicillin, 1 million units b.d.. together with streptomycin $1 \mathrm{~g}$. daily, which were continued till the 94th day, by which time the patient was again well and up for five hours daily. The penicillin dose was continued till the 103rd postoperative day, when the patient was considered fit for discharge. On the 107th day there was a further slight relapse with low-grade pyrexia, which was successfully treated with 2 million units of penicillin, sixhourly, with " benemid." On this occasion, however. the penicillin was continued till the $151 \mathrm{st}$ postoperative day. The patient was discharged 10 days later and has since remained well.

CASE 5.-W. G., a man, aged 46 years, was admitted with a past history of rheumatic fever at the age of 20 , and, at the age of 25 , a sudden right hemiplegia with aphasia, from which he made a good recovery. His chief complaints were increasing dyspnoea on exertion, orthopnoea and paroxysmal nocturnal dyspnoea, which he dated from a severe road accident eight years previously. On examination he had the signs of mitral stenosis with insignificant mitral leak and without failure.

Mitral valvotomy was attempted, but a very long funnel-shaped valve with very tough and matted $ᄋ$ chordae allowed only dilatation of the valve and no split was achieved. On the fifth post-operative day he felt better than before the operation, and the extremities were warmer.

Thirteen days after operation. because pulmonary infarction was diagnosed after the development of sudden chest pain, the expectoration of rusty sputum and slight elevation of the jugular venous pressure. anticoagulants were begun.

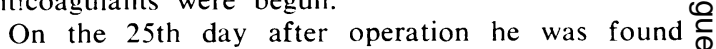
collapsed and dyspnoeic and further pulmonary embolism was diagnosed. Forty-eight hours later he became pyrexial, and, as a superimposed bacterial $\overline{0}$ endocarditis was considered, blood culture was taken, $\overrightarrow{\mathbb{D}}$ which grew a pure growth of coagulase-negative staphy- $\frac{\mathcal{O}}{\square}$

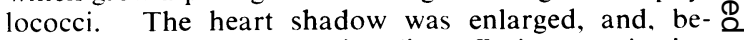
cause of a possible pericardial effusion, aspiration 
was attempted, but only blood from the right ventricle was obtained. This was sent for culture and grew Streptococcus viridans. On the 31 st day he appeared well and the anticoagulants were discontinued. On the 42nd day, however, he had further pain in the left upper chest, and, though he was still apyrexial, penicillin and streptomycin were given. Red blood cells were repeatedly noted in the urine at this time. His appearance at this time was described as varying quite rapidly from good to moribund, with no specific signs. However, steady progress was made, and at the end of four weeks of penicillin and streptomycin treatment he remained well and was discharged two weeks later.

CASE 6.-M. M., a woman aged 43 years, was admitted to hospital with a past history of growing pains at the age of 11 years, and rheumatic fever at the age of 21 years. Her symptoms began in her second pregnancy, five years previously, when she became dyspnoeic on exertion and suffered from tiredness and weakness. She was orthopnoeic and had paroxysmal nocturnal dyspnoea. On investigation she was found to have pure mitral stenosis. Mitral valvotomy was performed, a good split of both commissures being obtained. Following operation she was kept on penicillin, 0.5 million units b.d., for ten days, and during this period she remained well, apart from the development on the seventh day of a large area of inflammation in the left buttock at the site of a penicillin injection. This subsided slowly with conservative treatment. The temperature rose to $99^{\circ} \mathrm{F}$. about this time. The patient continued to make good progress, but on the fourteenth post-operative day the temperature rose to $100.2^{\circ} \mathrm{F}$. and continued to swing to this level, and there was slight general malaise. The patient looked well; there was no change in the cardiac signs, there was no splenomegaly, no petechiae, no anaemia, no red cells in the urine, and the optic fundi were normal. Blood taken for culture on two occasions grew a coagulasenegative Staphylococcus albus, which was not sensitive to penicillin, slightly sensitive to aureomycin and terramycin, moderately sensitive to chloramphenicol, and fully sensitive to erythromycin. Treatment with terramycin, $0.5 \mathrm{~g}$. six-hourly, produced no change in the pyrexia, and erythromycin replaced it after three days with prompt good effect. This was continued for six weeks.

CASE 7.-L. W., a woman aged 47 years, was admitted with a history that nine years previously she had been diagnosed as mitral stenosis in cardiac failure, with myxoedema. Treatment of these conditions with digitalis and thyroid caused a remarkable improvement in her condition.

Her condition deteriorated several months before her admission, exertional dyspnoea returned, and she was orthopnoeic. On examination she had the signs of mitral stenosis with considerable incompetence, auricular fibrillation, and gross cardiomegaly. After 10 days' treatment, mitral valvotomy was performed and a satisfactory valvotomy was carried out without increase in the mitral leak. The atrium was closed by suture with atraumatic silk.

A superficial wound infection due to Staphylococcus aureus, sensitive to aureomycin and terramycin but not sensitive to penicillin, was the only event in the postoperative course. This was satisfactorily treated by penicillin and then terramycin.

She convalesced satisfactorily, and on the 47th day, when it was planned that she should be discharged, she died suddenly while in conversation with a relative.

Relevant Post-mortem Findings.-The heart was enlarged $(550 \mathrm{~g}$.) due to hypertrophy of the right ventricle and right and left atria, which were also dilated. In the left auricle was a chronic abscess, $2 \mathrm{~cm}$. in diameter, containing suture material (Fig. 4). From this Staphylococcus pyogenes was isolated, together with a scanty growth of Streptococcus viridans, and diphtheroids. The mitral valve was thickened and adherent, with shortening of the chordae tendinae. There was evidence of a partial splitting at valvotomy, but no vegetations.

The coronary arteries and pulmonary arteries were normal. The lungs showed haemosiderosis and there was an early diffuse hepatic fibrosis.

Death was considered to be due to ventricular fibrillation associated with a subepicardial abscess.

CASE 8.-G. V., a girl aged 18 years, had known from infancy that there was something wrong with her heart and had never played games. She was a little dyspnoeic on hurrying, but had no other symptoms. On examination patent ductus arteriosus with a large shunt was confidently diagnosed. At operation a very short ductus, $0.5 \mathrm{~cm}$. in diameter, was dissected. Two ligatures of No. 5 silk were passed around it and tied firmly, but it was not possible to separate them. They were cut, leaving the ends long. The chest was closed without drainage and without securing the pericardium, which had been opened, or the pleura over the ductus.

The post-operative course was satisfactory, and on the 19th day she was discharged home. There she remained well until three days later, when she developed a pain across the front of the chest, followed 48 hours later by haemoptysis and a high pyrexia $\left(104^{\circ}-105^{\circ} \mathrm{F}\right.$.).

On the 20th day she was readmitted, looking pale, desperately ill, and anxious; the temperature was $105^{\circ} \mathrm{F}$. There was diminished air entry to the left lung and there was a faint systolic murmur in the pulmonary area. A postero-anterior radiograph of the chest showed a clearly defined opacity extending from the left hilum (Fig. 5). A diagnosis of traumatic false aneurysm from the ligatured ductus was made. In the next two days the patient became more seriously ill and continued to have haemoptyses. The radiograph showed a definite increase in the size of the opacity.

On the 28th day it was felt that the only possible thing that could help the patient would be reexploration, and that there was little chance of achieving anything even then. The chest was opened by 
FIG. 4.- Localized abscess in auricular wall in Case 7. Suture material visible within the abscess.

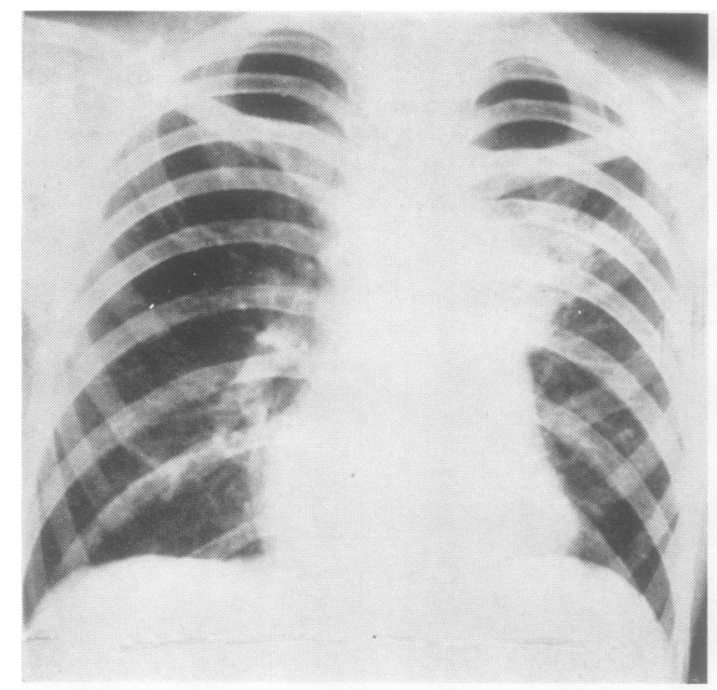

(a)

Figs. $6 a$ and $b$.-Postero-anterior and left lateral chest radiographs of Case 9 taken 25 days after ligation of the ductus and showing a lesion of the anterior segment of the left upper lobe. 
an anterior approach, as it was felt this would give a better chance of reaching the great vessels without disturbing the false aneurysm. A flap was raised and the lung drawn backwards. Very soon the false aneurysm was seen. Its wall consisted only of thin blood clot, and as soon as it was touched all the patient's blood came out.

The false aneurysm was about $5 \mathrm{~cm}$. in diameter; it had infiltrated the lung and thus caused the haemoptysis. Loosely floating within it were the two ligatures that had been placed on the ductus. No trace whatever of this structure could be seen. Its two ends were marked by holes, that in the aorta being about $3 \mathrm{~mm}$. in diameter, and that in the pulmonary artery being ragged and about $7 \mathrm{~mm}$. in diameter. The ligatures and some of the surrounding tissues were sent for culture.

Post-mortem examination confirmed the operative findings and revealed moderate left ventricular hypertrophy and infected thrombus in the false aneurysm.

Culture of the ligatures and the adjacent tissue gave a profuse growth of Staphylococcus aureus not sensitive to penicillin.

CASE 9.-G. D., a girl aged 9 years 10 months, was diagnosed during routine examination, at the age of 9 years, as having a patent ductus arteriosus. On investigation it was considered that there was a marked shunt and the ductus was ligated under penicillin cover, using triple floss silk ligatures. The ductus was short and wide and the surgeon felt unhappy concerning the aortic ligature, which he thought was tight and close to the aortic wall, which was thin and aneurysmal.

Convalescence, however, was uneventful except for a low-grade, irregular fever. Penicillin was discontinued after 18 days, and a week later chest radiographs revealed a segmental opacity in the left upper lobe (Fig. $6 a$ and $b$ ). The patient was now pyrexial $\left(104^{\circ} \mathrm{F}\right.$.), with a polymorphonuclear leucocytosis (W.B.C. $15,000 /$ c.mm., $91 \%$ polymorphs).

Terramycin, $250 \mathrm{mg}$. six-hourly, was begun, but on the same day there was a $6 \mathrm{oz}$. haemoptysis. During the next week pyrexia $\left(101^{\circ}-102^{\circ} \mathrm{F}\right.$.) continued, with daily haemoptyses. Blood culture was negative. On the 32nd post-operative day terramycin was discontinued and streptomycin and penicillin therapy instituted. By now the child's condition was much improved and the temperature near normal, but there was an anaemia (Hb 68\%, 10.06 g.). Chest radiographs still showed the lesion in the left upper lobe, but there were no definite abnormal signs. On the 41 st postoperative day she suffered a further small haemoptysis, followed by several larger ones, culminating in a massive fatal haemorrhage.

Necropsy.-The trachea, main bronchi, and stomach contained much bright red blood. The pulmonary artery opening of the ductus was occluded by organizing thrombus and its pulmonary site of origin endothelialized. The aortic end, however, was still open and communicated with a large thrombus-filled, irregular "false aneurysmal" cavity, $5 \mathrm{~cm}$. in diameter.
This false aneurysm tracked into the hilum of the left upper lobe and communicated with a segmental bronchus. The silk ligatures were found in this cavity.

The thrombus sectioned was infected and on culture yielded a scanty growth of Streptococcus viridans and coagulase-positive staphylococci. Death was due to haemorrhage from a false aneurysm of the ductus.

\section{BACTERIOLOGICAL INVESTIGATION}

In an attempt to evaluate the relative importance of various possible sources of infection, the staphylococcal flora of the staff, the patients, the operating theatre, and the wards were investigated in one hospital.

Of all the medical and nursing staff investigated, $50 \%$ grew coagulase-positive staphylococci from nasal swabs, and it was rare not to isolate a staphylococcus (including coagulase-negative staphylococci). Most of these were resistant to penicillin, but all, with one exception, were sensitive to aureomycin and terramycin.

In a random sample of patients awaiting operation the nose swabs revealed a staphylococcal carrier rate of $68 \%$, of which $70 \%$ were resistant to aureomycin and terramycin as well as penicillin.

In the operating theatre it was found that, while at the beginning of the operation the surgeons' gloves and suture material were free from organisms, at an early stage in the operation there was widespread contamination which increased as the operation proceeded. Thus the gloves, the finger used for valvotomy, all handled suture material, packs used in the chest, and the intravenous drip were all found to produce a profuse growth of staphylococci, usually coagulase-negative and astonishingly frequently sensitive to all the antibiotics, including penicillin. Skin sterilization proved to be efficient. This staphylococcal contamination was not surprising in view of the fact that plates exposed in the theatre yielded a heavy, almost pure growth of staphylococci, the majority of which were coagulasenegative and sensitive to all antibiotics.

Ward and other procedures studied included cardiac catheters, before and after use, and intravenous apparatus in use. The catheters were sterile, but coagulase-negative staphylococci were isolated from a few millilitres of blood delivered into a culture bottle from a transfusion set in operation.

\section{Discussion}

The usual concept of bacterial endocarditis is of an acute fulminating type variously known as acute bacterial, malignant, or ulcerating endocarditis, usually due to pyogenic organisms, and 
subacute bacterial endocarditis, a more slowly progressive disease, usually due to non-pyogenic organisms, the commonest of which is the Streptococcus viridans. However, there is no clear-cut distinction clinically or bacteriologically. Streptococcus viridans, Haemophilus influenzae, and Staphylococcus albus may cause the acute variety (Anderson, 1948) and staphylococci have been reported as a cause of the subacute variety (Cates and Christie, 1951 ; Harris and Fishburn, 1952). Wood (1950) considers this classification into two types artificial, the course of the disease depending on the virulence of the organism and the resistance of the host, and, in the absence of a clear-cut division, thinks they are best considered as one disease. We likewise do not attempt to draw a distinction between the acute and subacute forms.

Though the aetiological relationship between minor operations, such as tonsillectomy and dental extraction, and the development of streptococcal bacterial endocarditis on an abnormality of the cardiovascular system has been well recognized, very little attention has been paid to the possibility of bacterial endocarditis complicating direct interference with the heart and great vessels. Theoretically this could be expected to happen frequently, because in all such operations the endothelium is of necessity damaged and an opportunity afforded for infection by organisms, particularly the ubiquitous staphylococcus. It may be noted that all our cases had escaped the complication of bacterial endocarditis until the post-operative period (cf. Bailey and others, 1952). The frequency of this occurrence cannot be accurately judged, but that it is not uncommon is suggested by the ease with which we have gathered nine cases. These cases have not arisen in one hospital or from one surgeon, but from four hospitals and in the practice of five different surgeons, detracting from the frequency, as these are drawn from several hundred cardiac operations. But the distribution of the cases amongst several hospitals and surgeons, without a particular sepsis problem, suggests that this complication is not a particular local happening.

Staphylococci may produce a slowly progressive endocarditis such as in the case lasting over two years described by Blog, Connor, Newman, and Kenney (1955), but it is more usually a severe and rapidly fatal condition with a poor prognosis. Wilhelm, Hirsh, Hussey, and Dowling (1947) without antibiotics found a $25 \%$ mortality, the fatal cases having a rapidly progressive illness lasting no longer than six weeks. Levinson, Griffith, and Pearson (1950) found a mortality of $66 \%$ in a series of 18 patients treated with penicillin, and many of their cases were dead within three weeks. Our findings conform with this pattern, five of our nine cases proving fatal, all but one of these within three weeks from the onset of the illness, the exception being Case 8, a sudden death with myocardial abscess. This high mortality is probably not inevitable, as in Levinson's fatal cases the causative organism was always penicillin resistant. Similarly in our cases many of the deaths may be attributed to the treatment of the condition by drugs to which the organism was resistant when there still remained

TABLE

BACTERIOLOGICAL FINDINGS IN NINE CASES OF INFECTION FOLLOWING CARDIAC SURGERY

\begin{tabular}{|c|c|c|c|c|c|c|}
\hline $\begin{array}{l}\text { Case } \\
\text { No. }\end{array}$ & $\begin{array}{l}\text { Organism } \\
\text { Recove:ed }\end{array}$ & $\begin{array}{l}\text { Coagulase } \\
\text { Reaction }\end{array}$ & Source & $\begin{array}{l}\text { Antibiotic } \\
\text { Sensitivity }\end{array}$ & $\underset{\text { to }}{\text { Resistant }}$ & $\begin{array}{l}\text { Antibiotic } \\
\text { Used }\end{array}$ \\
\hline 1 & Staphylococcus & - ve & $\begin{array}{l}\text { Blood culture } \\
\text { and necropsy }\end{array}$ & Chloramphenicol & $\begin{array}{l}\text { Penicillin, aureomycin, } \\
\text { terramycin, strepto- }\end{array}$ & Penicillin \\
\hline 2 & ", & $+\mathbf{v e}$ & Blood culture & $\begin{array}{l}\text { Terramycin, chloram- } \\
\text { phenicol, erythro- }\end{array}$ & Penicillin & $\begin{array}{l}\text { Penicillin, chloramphen- } \\
\text { icol }\end{array}$ \\
\hline 3 & , & , & Necropsy & Not done & & $\begin{array}{l}\text { Penicillin, terramycin, } \\
\text { aureomycin, chloram- } \\
\text { phenicol }\end{array}$ \\
\hline 4 & , & , & Blood culture & $\begin{array}{l}\text { Penicillin, chloram- } \\
\text { phenicol }\end{array}$ & $\begin{array}{l}\text { Aureomycin, terramy- } \\
\text { cin, streptomycin }\end{array}$ & $\begin{array}{l}\text { Penicillin, streptomycin, } \\
\text { chloramphenicol }\end{array}$ \\
\hline 5 & $\begin{array}{l}\text { Staphylococcus and Strep- } \\
\text { tococcus viridans }\end{array}$ & - ve & & Not done & & Penicillin, streptomycin \\
\hline 6 & Staphylococcus & , & , , & $\begin{array}{l}\text { Erythromycin, partial } \\
\text { to chloramphenicol, } \\
\text { aureomycin, and } \\
\text { terramycin }\end{array}$ & Penicillin & $\begin{array}{l}\text { Penicillin, terramycin, } \\
\text { erythromycin }\end{array}$ \\
\hline 7 & $\begin{array}{l}\text { Staphylococcus, Strepto- } \\
\text { coccus viridans, and } \\
\text { diphtheroids }\end{array}$ & + ve & $\begin{array}{l}\text { Wound and } \\
\text { necropsy }\end{array}$ & $\begin{array}{l}\text { From wound, aureo- } \\
\text { mycin and terra- } \\
\text { mycin }\end{array}$ & ", & Penicillin, terramycin \\
\hline $\begin{array}{l}8 \\
9\end{array}$ & $\begin{array}{l}\text { Staphylococcus } \\
\text { Staphylococcus and Strep- } \\
\text { tococcus viridans }\end{array}$ & ", & $\begin{array}{l}\text { Necropsy } \\
\quad,\end{array}$ & $\begin{array}{l}\text { Not done } \\
, \quad,\end{array}$ & ", & $\begin{array}{l}\text { Penicillin } \\
\text { Penicillin, streptomycin, } \\
\text { terramycin }\end{array}$ \\
\hline
\end{tabular}


an effective drug, judged by laboratory sensitivity tests (see Table). The patients who recovered all received the appropriate effective drug.

\section{Clinical Features}

Staphylococcal endocarditis appears within two to three weeks of mitral valvotomy, and the clinical picture does not conform with the usual conception of bacterial endocarditis in that clubbing, splenomegaly, Osler's nodes, and changes in the optic fundi were never present and petechiae were most unusual ; the cardiac murmurs remained unchanged throughout. The absence of these features has also been noted in spontaneous staphylococcal endocarditis by Dowling and others (1952) and Friedberg and Bader (1951). However, microscopic haematuria was frequently present. Unexplained fever and lack of well-being will, in the early stages, be the only suggestive features. Later, hectic fever, rapid deterioration in general condition, possibly with anaemia and jaundice, progressing to mental confusion and incontinence with death in coma, ensue. Symptoms and signs attributable to pulmonary infarction complicate the picture and distract the clinician's attention from the infective nature of the illness. Presumed pulmonary infarction was treated by anticoagulants in Cases $1,2,3,4$, and 5 , and preoccupation with these chest symptoms and signs caused staphylococcal endocarditis to be overlooked in Cases 1 and 3 and the diagnosis to be delayed in Cases 2,4 , and 5 .

However, in those cases $(2,4,5$, and 6$)$ successfully treated, the blood culture was positive at the early stage of general malaise and unexplained fever, and, if the appropriate drug can be administered at this time, the disease can be quickly controlled (see Case 6).

Though accompanied by the systemic manifestations of malaise and high fever, false aneurysm formation, the local complication of ligation of the ductus arteriosus, was diagnosed by the occurrence of haemoptysis and the appearance of a new radiographic shadow at the operation site. Staphylococcal infection was not suspected in either case during life, though cultures were done during antibiotic therapy in Case 9 to exclude streptococcal infection of the ductus. It would be interesting to know whether a staphylococcal bacteriaemia forms part of the picture.

There were no distinctive clinical features suggesting serious infection in Case 6, where sudden death occurred in a symptom-free patient harbouring a localized myocardial abscess.

\section{Pathology}

The pathology of our two fatal mitral cases was similar in so far as there were exuberant vegetations on the mitral valve containing numerous colonies of staphylococci, and in the general distribution of infarction. However, there was a marked contrast in the nature of these infarcts, which were septic in Case 3 and bland in Case 1, the causative organism being respectively coagulase-positive and coagulase-negative staphylococci. Widespread thrombosis (leg veins, pulmonary arteries, and left auricle) was a feature of Case 1, which developed during a period of well-controlled anticoagulant therapy, suggesting the possibility that staphylococcal cardiovascular infection may in some way encourage thrombus formation.

The pathogenesis of this staphylococcal infection of mitral valves and ligated ductuses shortly after operation would appear to depend on two factors, local operative trauma, particularly to the endothelium and endocardium, and the opportunity offered for the entry of organisms. The importance of these two factors is difficult to evaluate, particularly in the individual case.

Endocarditis is well known to affect damaged valves far more frequently than normal valves; this has also been shown to be the case for staphylococcal endocarditis (Blog and others, 1955), and cardiac surgery is an added trauma. Infection of a vessel wall is a well recognized cause of local aneurysm formation. In Case 8 the false aneurysm of the ductus was attributed by the surgeon to the infection, and the staphylococci were recovered from suture material taken from the aneurysm at operation. In Case 9, however, the surgeon (D.M.E.T.) considers that the mechnical factor of a tight aortic limb ligature was the important factor. In this case the isolation of organisms from within the false aneurysm at necropsy loses much of its significance, as the aneurysm was in open communication with a segmental bronchus. Further slight support to the importance of operative trauma is that most of the mitral valvotomies were more than usually difficult and prolonged.

\section{BACTERIOLOGY}

In every case a staphylococcus was isolated either during life or at necropsy (see Table). However, in three cases (5, 7, and 9) Streptococcus viridans was isolated in addition, and, as this organism is a well accepted cause of bacterial endocarditis, its presence cannot be ignored. Although we can find no reference to mixed 
infection in bacterial endocarditis, we feel that these are examples of such. This is not surprising, as presumably the organisms gain entry at the time of operation, when the environment is not limited to one bacterial species.

Of the nine cases, in three the staphylococcus was coagulase-negative, and failure to recognize the pathogenicity of this latter group led to the inadequate treatment of Case 1, these organisms being interpreted as contaminants. A search of the literature shows that the commonly accepted nonpathogenicity of coagulase-negative staphylococci is now entirely unjustified with reference to endocarditis. Cates and Christie (1951) found four cases of coagulase-negative staphylococci in their series of 408 cases of subacute bacterial endocarditis, though coagulase testing was not carried out on all staphylococci isolated. Dowling and others (1952) in 76 cases of staphylococcal endocarditis found 64 were due to Staphylococcus aureus and 12 to Staphylococcus albus ; 19 of the staphylococci were coagulase-positive and seven were negative, and they found little difference in the course of the disease due to these variants. Levinson and others (1950) also reported $50 \%$ of their staphylococci as Staphylococcus albus and considered the endocarditis due to the latter to have a more protracted course. From the laboratory it has been shown (Smith, Morrison, and Lominski, 1952; Lack and Wailling, 1954) that coagulase production is an irregular feature and there is no unbridgable gap between coagulasepositive and -negative staphylococci and that such coagulase production is not closely related to pathogenicity. O'Hare and Stevenson (1953) also emphasize this in the report of a case of bacterial endocarditis due to a Staphylococcus albus.

\section{Sensitivity to AnTiBiotics}

The importance of detailed determination of the sensitivity of the organisms is emphasized by the great frequency of resistance of the organisms to penicillin and the increasing frequency of resistance to the newer antibiotics. The development of penicillin-resistant staphylococci has been well shown by the work of Barber and RozwadowskaDowzenko (1948) and Beigelman and Rantz (1950), who showed well over half of the hospital staphylococci to be penicillin-resistant. This problem is not limited to penicillin, and resistance has been shown to develop to all antibiotics suitable for systemic administration (Lowbury, 1955). Fusillo, Noyes, Pulaski, and Tom (1953) have pointed out that it is rare to find staphylococci completely resistant to chloramphenicol.
This is no doubt due to the sparing use of chloramphenicol, which is rarely used as an operative cover and seldom to treat minor staphylococcal infections because of its notorious toxic effects. All but one of the staphylococci recovered from our nine patients were penicillin-resistant (see Table), which might be expected, as penicillin operative cover was used routinely. Unfortunately full sensitivity tests are not available in sufficient of our cases to permit conclusions to be drawn, but chloramphenicol was active in vitro in every case when tested, and in Case 2 was the only effective antibiotic.

Erythromycin and bacitracin, effective antistaphylococcal agents, may have to be employed, as in Case 7.

\section{SOURCES OF INFECTION}

It is clear that the operating theatre is a possible source of infection and the staphylococcal population, particularly of coagulase-negative staphylococci, was surprisingly large. Though a high percentage of penicillin-resistant staphylococci were recovered from the staff and patients, penicillin-sensitive coagulase-negative staphylococci were the main air-borne organisms which contaminated sutures, swab, and glove, appearing to justify the continued use of penicillin operative cover. This cover will at least greatly reduce the effective innoculum of organisms.

Many other methods of reducing the staphylococcal population during operations have recently been advocated (Lowbury, 1955). Of these the most important is the introduction of positive pressure filtered air ventilation (Cairns, 1939). The result of the evaluation of the efficiency of this, compared with the orthodox extraction ventilation, by Drs. Sevitt and Lowbury (Lowbury, 1955) will be awaited with interest. In view of the possible staphylococcal complications of cardiac surgery, it is essential that all possible methods of reducing the opportunities of operative infection are carried out.

However, the theatre is not the only possible source of infection, as modern investigation and treatment involve repeated breach of the skin surface, offering ample opportunity for the entry of organisms. Care should be exercised with all intravenous manipulations so that the ever present staphylococcus is not introduced into the circulation. A number of cases of staphylococcal endocarditis have been reported in heroin addicts who administer their drug intravenously (Wilhelm and others, 1947). This series illustrates the care with which simple ward procedures, such as blood 
transfusion, the administration of heparin, and venepuncture for prothrombin times, should be carried out. Even intramuscular injections are not free from suspicion, as illustrated by our Case 6, where inflammation at the site of penicillin injection was the first sign of infection. Later penicillin-resistant staphylococci were grown on blood culture.

\section{SUMmary AND CONCLUSIONS}

Nine cases of staphylococcal infection of the heart and great vessels following cardiac surgery are described; five were fatal, two being due to endocarditis following mitral valvotomy, two due to rupture of a false aneurysm of a ligated ductus, and one was an unexpected sudden death with a myocardial abscess following mitral valvotomy. Four patients recovered after appropriate antibiotic therapy.

The diagnosis in the mitral cases can be made in the early stages when fever and failure to do well are the only features, but blood cultures are positive at this stage. Chest pain with haemoptyses, high fever, anaemia, jaundice, and mental changes were the later salient features of staphylococcal endocarditis. Confusion may arise from the presence of the signs of pulmonary infarction. False aneurysm formation of the ligated ductus was signalled by an increasing radiological opacity and repeated haemoptyses with fever. The possible role of infection in the pathogenesis of this is discussed.

The pathogenicity of coagulase-negative staphylococci in connexion with endocarditis is emphasized and the relative importance of mechanical trauma and infection is discussed.

The necessity of determining the antibiotic sensitivity of causative organisms and the possible sources, and methods of reducing the risk, of infection are briefly discussed.

Our thanks are due to the following physicians, surgeons, and pathologists for access to the records and to the cases under their care : Mr. N. R.
Barrett, Dr. F. E. Camps, Dr. Byron Evans, Mr. H. R. S. Harley, Dr. A. G. Heppleston, Dr. A. J. Thomas, Mr. Dillwyn M. E. Thomas, Mr. T. Savage, Dr. H. Spencer, and Dr. L. R. West.

Thanks are also due to Dr. H. M. Foreman, Physician Superintendent of Sully Hospital, for permission to publish, to Mrs. B. Marshall and Mr. J. P. Napper for the photographs, and to Miss E. M. Jackson for the typing.

\section{REFERENCES}

Anderson, W. A. D. (1948). Pathology. Mosby, St. Louis.

Bailey, C. P., Bolton, H. E., and Redondo-Ramirez, H. P. (1952). Surg. Clin. N. Amer., 32, 1807.

Baker, C., Brock, R. C., Campbell, M., and Wood, P. (1952). Brit. med. J., 1, 1043.

Barber, M., and Rozwadowska-Dowzenko, M. (1948). Lancet, 2, 641 .

Beigelman, P. M., and Rantz, L. A. (1950). New Engl. J. Med.,

Blog, H. C., Connor, C. A. R., Newman, W., and Kenney, M. (1955). Ibid., 252, 185.

Cairns, H. (1939). Lancet, 1, 1193.

Cates, J. E., and Christie, R. V. (1951). Ouart. J. Med., $20,93$.

Dowling, H. F., Lepper, M., Caldwell, E. R., and Spies, H. W. (1952) Medicine, Baltimore, $31,155$.

Friedberg, C. K., and Bader, M. E. (1951). J. Amer. med. Ass., $147,46$.

Fusillo, M. H., Noyes, H. E., Pulaski, E. J., and Tom, J. Y. S. (1953) Antibiot. and Chemother., 3, 581 .

Harris, W. H., and Fishburn, G. W. (1952). Amer. Heart J., 43, 474

Lack, C. H., and Wailling, D. G. (1954). J. Path. Bact., 68, 431.

Levinson, D. C., Griffith, G. C., and Pearson, H. E. (1950). Circulation, 2,668 .

Lowbury, E. J. L. (1955). Brit. med. J., 1, 985

Lowbury, E. J. L. (1955). Brit. med. J., 1, 985.

Sellors, T. Holmes, Bedford, D. E., and Somerville, W. (1953). Lancet, 2, 1059.

Smith, D. D., Morrison, R. B., and Lominski, I. (1952). J. Path. Bact., 64, 567.

Wilhelm, F., Hirsh, H. L., Hussey, H. H., and Dowling, H. F. (1947) Ann. intern. Med., 26, 221

Wood, P. (1950). Diseases of the Heart and Circulation. Eyre and Spottiswoode, London. (1954). Brit. med. J., 1, 1051.

\section{ADDENDUM}

Since this paper was completed, Blowers, Mason, Wallace, and Walton (1955) have published a detailed account of the investigation and control of wound infection in a thoracic surgical unit. They examined many sources of infection and agree with our findings that the operating theatre is very important. Methods of control are considered in detail.

\section{REFERENCE}

Blowers, R., Mason, G. A., Wallace, K. R., and Walton, M. (1955). Lancet, 2, 786. 